\title{
Effects of operational variables on rotary valve metering system for a variable rate technology fertilizer applicator for oil palm
}

\begin{abstract}
In the Malaysian oil palm plantation, fertilizer application was observed to be done manually or mechanically at uniform rate without due consideration to nutrient variability. The available constant rate mechanical fertilizer spreaders on oil palm plantation were found to be susceptible to excessive fertilizer application. On the other hand, Variable Rate Technology (VRT) could be used to forestall the hazards of excessive fertilizer application. However, full knowledge of the operational variables of the metering system of a VRT applicator has become inevitable for proper utilization of this technology. A rotary valve metering system test rig was designed and constructed for the purpose of studying the characteristics of the system. A linear regression equation was developed to relate the discharge rate of the metering system to the screw conveyor speed, rotary valve speed, fertilizer bulk density and repose angle. The coefficient of determination (R2) of the regression equation was $98.65 \%$. The screw conveyor speed, the rotary valve speed and type of fertilizer were found to have statistically significant effect on the discharge rate of the system. It was observed that the discharge rate of the system decreased with increase in rotary valve speed. The outcome of this study will enhance the use of rotary valve in the VRT fertilizer applicator for oil palm.
\end{abstract}

Keyword: Variable rate technology; Rotary valve; Fertilizer; Oil palm 